\title{
PENGUKURAN NILAI RISIKO PORTOFOLIO BERDASARKAN MEAN-VaR
}

\author{
CITRA ARIADINI CHAIRUNNISA, HAZMIRA YOZZA, DODI DEVIANTO \\ Jurusan Matematika, \\ Fakultas Matematika dan Ilmu Pengetahuan Alam, Universitas Andalas, \\ Kampus UNAND Limau Manis Padang, Indonesia. \\ email : citraariadini8@gmail.com
}

\begin{abstract}
Abstrak. Portofolio merupakan kumpulan dari beberapa investasi saham. Portofolio terbaik adalah portofolio dengan mean return dan risiko saham yang terbaik. Salah satu metode dalam mengukur nilai risiko adalah dengan Value at Risk(VaR). VaR didefinisikan sebagai tingkat kerugian maksimal atau return minimal pada tingkat kepercayaan yang cukup tinggi untuk waktu tertentu. Jika seorang investor membentuk portofolio maka berarti investor menentukan proporsi dana yang diinvestasikan pada masingmasing saham. Investor menginvestasikan dana pada masing-masing saham dengan total proporsi dana adalah 1. Permasalahan dalam menghitung proporsi dana dapat menggunakan metode Pengganda Lagrange. Dari 33 saham Perbankan yang terdaftar pada Bursa Efek Indonesia didapat komposisi portofolio yang terdiri dari Bank Danamon Indonesia Tbk, Bank Mandiri (Persero) Tbk dan Bank CIMB Niaga Tbk. Dari ketiga saham diperoleh proporsi investasi masing-masing dana yaitu 19,76\% Bank Danamon Indonesia Tbk, 60,34\% Bank Mandiri (Persero) Tbk dan 19,90\% Bank CIMB Niaga Tbk. Dari portofolio yang terbentuk didapat nilai risiko yaitu 0,001345. Hal ini berarti risiko dari portofolio yang terbentuk sangat kecil yaitu $0,13 \%$ sehingga aman bagi investor dalam berinvestasi.
\end{abstract}

Kata Kunci: Portofolio, Value at Risk, Pengganda Lagrange, Risiko

\section{Pendahuluan}

Investasi adalah penanaman modal untuk satu atau lebih sekuritas yang dimiliki dan biasanya berjangka waktu lama dengan harapan mendapatkan keuntungan di masa-masa yang akan datang [7]. Dari berbagai jenis investasi yang ada, masyarakat Indonesia lebih cenderung melakukan investasi berupa saham. Menurut [7], saham adalah surat berharga yang menjadi bukti bahwa seseorang telah berinvestasi pada suatu perusahaan. Saham merupakan surat bukti bahwa kepemilikan atas aset-aset perusahaan yang menerbitkan saham.

Salah satu karakteristik investasi berupa saham adalah kemudahan untuk membentuk kumpulan dari investasi. Kumpulan dari saham yang telah diinvestasikan oleh investor disebut portofolio. Portofolio yang baik adalah portofolio yang efisien. Portofolio ini didefinisikan sebagai portofolio yang memberikan ekspektasi (mean) return maksimal dengan nilai risiko tertentu atau memberikan risiko terkecil dengan mean return [3]. Portofolio efisien adalah portofolio yang baik namun bukan terbaik. Portofolio yang terbaik adalah portofolio optimal, yaitu suatu portofolio dengan mean return dan risiko yang terbaik. 
Untuk tujuan tersebut, investor harus dapat memperkirakan dengan tingkat keyakinan (level of confidence) dan dalam jangka waktu tertentu berapa risiko penurunan nilai return hal ini disebut juga dengan VaR (Value at Risk). VaR didefinisikan sebagai tingkat kerugian maksimal atau return minimal pada tingkat kepercayaan yang cukup tinggi untuk waktu tertentu. Dalam perhitungan VaR, return saham diasumsikan berdistribusi normal karena jika return saham tidak berdistribusi normal maka risiko yang ditimbulkan tidak stabil.

Untuk mendapatkan nilai risiko yang minimal berdasarkan Mean-VaR maka harus meminimumkan nilai VaR. Permasalahan dalam meminimumkan nilai VaR merupakan persoalan dalam optimisasi. Dalam membentuk portofolio, dana yang diinvestasikan pada masing-masing saham memiliki total proporsi dana sama dengan 1. Artinya dalam menentukan proporsi dana merupakan optimisasi dengan kendala. Karena total proporsi dana sama dengan 1 maka digunakan metode Pengganda Lagrange. Pada metode ini, dibentuk suatu fungsi baru, disebut fungsi Lagrange yang merupakan penjumlahan dari fungsi yang hendak dioptimumkan ditambah hasil kali pengganda Lagrange dengan fungsi kendalanya dan selanjutnya melakukan optimasi terhadap fungsi baru tersebut. Dalam penelitian ini pengukuran nilai risiko portofolio berdasarkan Mean-VaR.

\section{Landasan Teori}

\subsection{Teori Keuangan}

Saham merupakan hak kepemilikan atas aset-aset perubahan yang menerbitkan saham. Return saham adalah hasil yang diperoleh dari berinvestasi. Andaikan saham sekarang disimbolkan dengan $P_{j}$ maka Return yang dilambangkan dengan $R_{i}$ dapat dinyatakan sebagai

$$
R_{i}=\frac{P_{j}-P_{j-1}}{P_{j-1}}
$$

Dari Persamaan (2.1) diperoleh mean return saham yaitu

$$
E\left(R_{i}\right)=\frac{\sum_{j=1}^{n} R_{i j}}{n},
$$

dengan $R_{i j}$ merupakan return saham dari investasi ke- $i$ pada saat ke- $j$. Setiap saham yang diinvestasikan terkadang mengalami risiko. Dalam perhitungannya, risiko saham biasanya diukur dengan standar deviasi dari return saham yang dilambangkan dengan $\sigma$ dan dirumuskan sebagai

$$
\sigma_{i}=\sqrt{\frac{\sum_{j=1}^{m}\left[R_{i j}-E\left(R_{i}\right)\right]^{2}}{m}} .
$$

\subsection{Teori Portofolio}

Portofolio diartikan sebagai serangkaian kombinasi beberapa aktiva yang diinvestasikan dan dipegang oleh investor, baik perorangan maupun lembaga. Dengan melakukan kombinasi saham, investor bisa meraih return saham yang optimal dan 
memperkecil risiko [3]. Andaikan $w_{i}$ adalah proporsi dana yang dialokasikan pada saham $i$, dimana $\Sigma_{i=1}^{n} w_{i}=1$ maka return portofolio dapat dinyatakan sebagai

$$
R_{w}=\sum_{i=1}^{n} w_{i} R_{i}
$$

dimana $R_{i}$ merupakan return portofolio ke- $i$. Berdasarkan proporsi dana yang dialokasikan pada saham $i$ maka ekspektasi dari return portofolio yaitu :

$$
\mu_{w}=\sum_{i=1}^{n} w_{i} \mu_{i},
$$

dengan $\mu_{i}$ merupakan ekspektasi return saham ke- $i$.

Dalam membentuk portofolio, investor harus memperhatikan risiko yang dihasilkan. salahsatu metode untuk mengukur nilai risiko dengan Value at Risk (VaR). VaR didefinisikan sebagai tingkat kerugian maksimal atau return minimal pada tingkat kepercayaan yang cukup tinggi untuk waktu tertentu. Perhitungan VaR dapat dinyatakan sebagai

$$
\operatorname{VaR} R_{w}=z_{\alpha} \sigma_{w}-\mu_{w}
$$

dimana $z_{\alpha}$ merupakan kuantil $1-\alpha$ dari sebaran return dan $\alpha$ merupakan taraf nyata.

\subsection{Portofolio Optimal Berdasarkan Mean-VaR}

Untuk membentuk portofolio, investor harus menentukan bobot portofolio pada masing-masing saham. Dalam menentukan bobot portofolio dilakukan proses optimisasi. Proses optimisasi merupakan suatu proses untuk mencapai hasil yang optimal dengan memaksimumkan ataupun meminimumkan dari suatu fungsi. Proses optimisasi terhadap bobot portofolio dilakukan dengan memperhatikan nilai mean return tertentu dan meminimumkan nilai risiko Value at Risk.

Berdasarkan peubah yang diketahui, $E\left(R_{i}\right)$ sebagai ekspektasi return saham, $\sigma_{i j}$ sebagai kovarian antara saham ke- $i$ dengan saham ke- $j$ dan matriks kovarian disimbolkan dengan $\boldsymbol{\Sigma}$. Misalkan $w_{i}$ adalah proporsi dana yang akan dialokasikan pada saham ke- $i$, maka seluruh dana yang diinvestasikan adalah 100\%, asumsi tersebut dapat disimbolkan sebagai berikut

$$
\sum_{i=1}^{n} w_{i}=\mathbf{e}^{\mathbf{T}} \mathbf{w}=1
$$

dengan $\mathbf{w}$ adalah vektor kolom proporsi dana dari saham atau dapat ditulis $\mathbf{w}=$ $\left[w_{1}, w_{2}, \cdots, w_{n}\right], \mathbf{e}^{\mathbf{T}}$ adalah vektor baris yang seluruh entrinya adalah 1.

Dari asumsi tersebut diperoleh return, ekpektasi return dan variansi portofolio berturut-turut sebagai berikut:

$$
\begin{aligned}
R_{w} & =\sum w_{i} R_{i} \\
& =\mathbf{w}^{\mathbf{T}} \mathbf{R} \\
\mu_{w} & =E\left(R_{w}\right)=\boldsymbol{\mu}^{\mathbf{T}} \mathbf{w} \\
\sigma_{w}^{2} & =\operatorname{Var}\left(R_{w}\right)=\mathbf{w}^{\mathbf{T}} \mathbf{\Sigma} \mathbf{w}
\end{aligned}
$$


dimana $\boldsymbol{\mu}$ merupakan vektor kolom dari return dan $\boldsymbol{\Sigma}$ merupakan matriks kovarian dari return saham. Berdasarkan Persamaan (2.7) dan (2.8), maka Persamaan (2.6) dapat ditulis sebagai berikut

$$
\begin{aligned}
V a R_{w} & =z_{\alpha} \sigma_{w}-\mu_{w} \\
& =z_{\alpha}\left(\mathbf{w}^{\mathbf{T}} \boldsymbol{\Sigma} \mathbf{w}\right)^{1 / 2}-\boldsymbol{\mu}^{\mathbf{T}} \mathbf{w}
\end{aligned}
$$

Untuk memperoleh portofolio yang efisien, para praktisi menggunakan fungsi objektif sangat sederhana dengan memaksimalkan

$$
2 \tau \mu_{w}-V a R_{w}, \tau \geqslant 0
$$

dengan $\tau$ menunjukkan toleransi risiko dimana toleransi risiko merupakan tingkatan atau jumlah suatu risiko untuk dapat diterima oleh investor [11].

Berdasarkan Persamaan (2.7) dan (2.9), untuk investor dengan toleransi risiko $\tau \geqslant 0$ harus menyelesaikan persoalan optimasi

$$
\max \left\{2 \tau \boldsymbol{\mu}^{\mathbf{T}} \mathbf{w}-z_{\alpha}\left(\mathbf{w}^{\mathbf{T}} \boldsymbol{\Sigma} \mathbf{w}\right)^{1 / 2}+\boldsymbol{\mu}^{\mathbf{T}} \mathbf{w}\right\}
$$

dengan kendala $\mathbf{e}^{\mathbf{T}} \mathbf{w}=\mathbf{1}$.

Masalah di atas adalah masalah optimasi dengan kendala. Sehingga untuk mencari bobot optimal dari masalah di atas perlu didefinisikan fungsi Lagrange yaitu

$$
L(\mathbf{w}, \lambda)=(2 \tau+1) \boldsymbol{\mu}^{\mathbf{T}} \mathbf{w}-z_{\alpha}\left(\mathbf{w}^{\mathbf{T}} \mathbf{\Sigma} \mathbf{w}\right)^{1 / 2}+\lambda\left(\mathbf{e}^{\mathbf{T}} \mathbf{w}-1\right)
$$

dengan $\lambda$ merupakan pengganda Lagrange, sehingga diperoleh turunan pertama fungsi Lagrange terhadap $\mathbf{w}, \lambda$ sebagai berikut:

$$
\begin{aligned}
& \frac{\partial L}{\partial \mathbf{w}}=(2 \tau+1) \boldsymbol{\mu}-\frac{z_{\alpha}(\boldsymbol{\Sigma} \mathbf{w})}{\left(\mathbf{w}^{\mathbf{T}} \boldsymbol{\Sigma} \mathbf{w}\right)^{1 / 2}}+\lambda \mathbf{e}=\mathbf{0} \\
& \frac{\partial L}{\partial \lambda}=\mathbf{e}^{\mathbf{T}} \mathbf{w}-1=0 .
\end{aligned}
$$

Dari Persamaan (2.12) dapat ditulis

$$
\begin{gathered}
(2 \tau+1) \boldsymbol{\mu}-\frac{z_{\alpha}(\boldsymbol{\Sigma} \mathbf{w})}{\left(\mathbf{w}^{\mathbf{T}} \boldsymbol{\Sigma} \mathbf{w}\right)^{1 / 2}}+\lambda \mathbf{e}=\mathbf{0} \\
\frac{z_{\alpha}(\boldsymbol{\Sigma} \mathbf{w})}{\left(\mathbf{w}^{\mathbf{T}} \boldsymbol{\Sigma} \mathbf{w}\right)^{1 / 2}}=(2 \tau+1) \boldsymbol{\mu}+\lambda \mathbf{e} .
\end{gathered}
$$

Dengan mengalikan $\boldsymbol{\Sigma}^{-\mathbf{1}}$ ke Persamaan (2.14), diperoleh

$$
\begin{aligned}
\frac{z_{\alpha}\left(\boldsymbol{\Sigma}^{-\mathbf{1}} \boldsymbol{\Sigma} \mathbf{w}\right)}{\left(\mathbf{w}^{\mathbf{T}} \boldsymbol{\Sigma} \mathbf{w}\right)^{1 / 2}} & =(2 \tau+1) \boldsymbol{\Sigma}^{-\mathbf{1}} \boldsymbol{\mu}+\lambda \boldsymbol{\Sigma}^{-\mathbf{1}} \mathbf{e} \\
\frac{z_{\alpha} \mathbf{w}}{\left(\mathbf{w}^{\mathbf{T}} \boldsymbol{\Sigma} \mathbf{w}\right)^{1 / 2}} & =(2 \tau+1) \boldsymbol{\Sigma}^{-\mathbf{1}} \boldsymbol{\mu}+\lambda \boldsymbol{\Sigma}^{-\mathbf{1}} \mathbf{e} \\
\mathbf{w} & =\frac{\left(\mathbf{w}^{\mathbf{T}} \boldsymbol{\Sigma} \mathbf{w}\right)^{1 / 2}}{z_{\alpha}}\left[(2 \tau+1) \boldsymbol{\Sigma}^{-\mathbf{1}} \boldsymbol{\mu}+\lambda \boldsymbol{\Sigma}^{-\mathbf{1}} \mathbf{e}\right]
\end{aligned}
$$

Persamaan (2.13) dapat ditulis menjadi

$$
\mathbf{e}^{\mathbf{T}} \mathbf{w}=1
$$


Dengan mengalikan $\mathbf{e}^{\mathbf{T}}$ ke Persamaan (2.15), diperoleh

$$
\frac{z_{\alpha} \mathbf{e}^{\mathbf{T}} \mathbf{w}}{\left(\mathbf{w}^{\mathbf{T}} \mathbf{\Sigma} \mathbf{w}\right)^{1 / 2}}=(2 \tau+1) \mathbf{e}^{\mathbf{T}} \boldsymbol{\Sigma}^{-\mathbf{1}} \boldsymbol{\mu}+\lambda \mathbf{e}^{\mathbf{T}} \boldsymbol{\Sigma}^{-\mathbf{1}} \mathbf{e}
$$

Berdasarkan Persamaan (2.17) maka Persamaan (2.18) dapat ditulis

$$
\begin{aligned}
& \frac{z_{\alpha}}{\left(\mathbf{w}^{\mathbf{T}} \boldsymbol{\Sigma} \mathbf{w}\right)^{1 / 2}}=(2 \tau+1) \mathbf{e}^{\mathbf{T}} \boldsymbol{\Sigma}^{-\mathbf{1}} \boldsymbol{\mu}+\lambda \mathbf{e}^{\mathbf{T}} \boldsymbol{\Sigma}^{-\mathbf{1}} \mathbf{e} \\
& \frac{\left(\mathbf{w}^{\mathbf{T}} \boldsymbol{\Sigma} \mathbf{w}\right)^{1 / 2}}{z_{\alpha}}=\frac{1}{(2 \tau+1) \mathbf{e}^{\mathbf{T}} \boldsymbol{\Sigma}^{-\mathbf{1}} \boldsymbol{\mu}+\lambda \mathbf{e}^{\mathbf{T}} \boldsymbol{\Sigma}^{-\mathbf{1}} \mathbf{e}} .
\end{aligned}
$$

Substitusi Persamaan (2.19) ke Persamaan (2.16) sehingga diperoleh

$$
\mathbf{w}=\frac{(2 \tau+1) \boldsymbol{\Sigma}^{-\mathbf{1}} \boldsymbol{\mu}+\lambda \boldsymbol{\Sigma}^{-\mathbf{1}} \mathbf{e}}{(2 \tau+1) \mathbf{e}^{\mathbf{T}} \boldsymbol{\Sigma}^{-\mathbf{1}} \boldsymbol{\mu}+\lambda \mathbf{e}^{\mathbf{T}} \boldsymbol{\Sigma}^{-\mathbf{1}} \mathbf{e}} .
$$

w merupakan proporsi portofolio dengan $\tau \geqslant 0$, dimana

$$
\lambda=\frac{-B \pm \sqrt{B^{2}-4 A C}}{2 A} .
$$

dengan $A=\mathbf{e}^{\mathbf{T}} \boldsymbol{\Sigma}^{-\mathbf{1}} \mathbf{e}, B=(2 \tau+1) \boldsymbol{\mu}^{\mathbf{T}} \boldsymbol{\Sigma}^{-\mathbf{1}} \mathbf{e}+\mathbf{e}^{\mathbf{T}} \boldsymbol{\Sigma}^{-\mathbf{1}} \boldsymbol{\mu}$, dan $C=(2 \tau+$ $1)^{2} \boldsymbol{\mu}^{\mathbf{T}} \boldsymbol{\Sigma}^{-\mathbf{1}} \boldsymbol{\mu}-z_{\alpha}^{2}[12]$

\section{Hasil dan Pembahasan}

Pada penelitian ini digunakan data saham Perbankan yang terdiri dari 33 saham Bank yang terdaftar pada Bursa Efek Indonesia. Dari 33 saham dihitung ekspektasi return dan risiko saham masing-masing, diperoleh

\begin{tabular}{|c|c|c|c|}
\hline Kode Saham & $E\left(R_{i}\right)$ & Kode Saham & $E\left(R_{i}\right)$ \\
\hline AGRO & $-0,001108$ & BNGA & $-0,001050$ \\
\hline BABP & 0,001438 & BNII & 0,000754 \\
\hline BACA & $-0,000040$ & BNLI & $-0,000286$ \\
\hline BBCA & $-0,001132$ & BSIM & $-0,000443$ \\
\hline BBKP & 0,000506 & BSWD & 0,001395 \\
\hline BBNI & $-0,001438$ & BTPN & 0,000250 \\
\hline BBRI & $-0,000922$ & DNAR & $-0,000801$ \\
\hline BBTN & $-0,001853$ & INPC & 0,000622 \\
\hline BBYB & 0,000381 & MCOR & 0,000362 \\
\hline BDMN & $-0,001141$ & MEGA & 0,000376 \\
\hline BEKS & 0,000869 & NAGA & 0,003518 \\
\hline BGTB & 0,000511 & NISP & 0,000302 \\
\hline BJBR & $-0,001039$ & NOBU & $-0,002758$ \\
\hline BJTM & $-0,000907$ & PNBN & $-0,001311$ \\
\hline BKSW & 0,004320 & PNBS & 0,003136 \\
\hline BMAS & 0,001183 & SDRA & 0,001849 \\
\hline BMRI & $-0,000794$ & &
\end{tabular}

Gambar 1. Data ekspektasi return saham Perbankan

Dalam penelitian ini digunakan juga saham pasar. Saham pasar yang digunakan adalah Indeks Harga Saham Gabungan atau IHSG. Data ekspektasi, risiko dan rasio dari saham pasar diberikan pada Gambar 3.

Untuk menentukan saham Perbankan yang baik digunakan rasio terhadap saham pasar. Rasio merupakan perbandingan antara ekspektasi dengan risiko saham. 


\begin{tabular}{|c|c|c|c|} 
Kode Saham & $\sigma_{i}$ & Kode Saham & $\sigma_{i}$ \\
\hline AGRO & 0,048021 & BNGA & 0,022757 \\
\hline BABP & 0,022422 & BNII & 0,021512 \\
\hline BACA & 0,009628 & BNLI & 0,027103 \\
\hline BBCA & 0,011503 & BSIM & 0,019565 \\
\hline BBKP & 0,015509 & BSWD & 0,050750 \\
\hline BBNI & 0,014677 & BTPN & 0,014288 \\
\hline BBRI & 0,014868 & DNAR & 0,057561 \\
\hline BBTN & 0,020208 & INPC & 0,035212 \\
\hline BBYB & 0,041965 & MCOR & 0,037597 \\
\hline BDMN & 0,021086 & MEGA & 0,022335 \\
\hline BEKS & 0,030045 & NAGA & 0,095318 \\
\hline BGTB & 0,045080 & NISP & 0,035683 \\
\hline BJBR & 0,039034 & NOBU & 0,017929 \\
\hline BJTM & 0,023253 & PNBN & 0,018983 \\
\hline BKSW & 0,067143 & PNBS & 0,022735 \\
\hline BMAS & 0,054790 & SDRA & 0,028459 \\
\hline BMRI & 0,014483 & & \\
\hline & \multicolumn{3}{|l}{} \\
\hline
\end{tabular}

Gambar 2. Data risiko saham Perbankan

\begin{tabular}{|c|c|c|c|}
\hline Kode Saham & $E\left(R_{i}\right)$ & $\sigma_{i}$ & Rasio \\
\hline IHSG & -0.000392 & 0.006737 & -0.058199 \\
\hline
\end{tabular}

Gambar 3. Data ekspektasi, risiko dan rasio saham Pasar

\begin{tabular}{|c|l|}
\hline Kode Saham & Nama Saham \\
\hline BDMN & Bank Danamon Indonesia Tbk \\
\hline BMRI & Bank Mandiri (Persero) Tbk \\
\hline BNGA & Bank CIMB Niaga Tbk \\
\hline
\end{tabular}

Gambar 4. Komposisi portofolio saham

Saham Perbankan yang baik adalah saham yang memiliki rasio lebih besar dari rasio pasar. Selanjutnya return saham dilakukan uji normalitas. sehingga diperoleh komposisi portofolio seperti pada Gambar 4.

Dari komposisi yang diperoleh dihitung bobot portofolio, ekspektasi portofolio dan Value at Risk dengan nilai toleransi risiko $\tau=0,0,1, \cdots$ diperoleh Gambar 5 .

Dari Gambar 6 dan Gambar 7 dapat dilihat hubungan antara Mean dan VaR portofolio berdasarkan nilai toleransi risiko melalui gambar berikut Berdasarkan sebaran return saham, terlihat bahwa dengan bertambahnya nilai toleransi risiko yang diberikan nilai ekspektasi return portofolio dan Value at Risk meningkat dan bobot portofolio masing-masing saham mengalami perubahan.

Bobot portofolio $w_{1}$ dan $w_{3}$ pada tabel mengalami penurunan seiring bertambahnya nilai toleransi risiko. Artinya ini menunjukkan bahwa bobot investasi pada $w_{1}$ dan $w_{3}$ menurun dengan meningkatnya nilai toleransi risiko. Namun pada $\tau=7,6$, proses optimasi dihentikan karena bobot portofolio $w_{1}$ menghasilkan bobot portofolio yang negatif.

Namun berbeda dengan $w_{1}$ dan $w_{3}$, bobot portofolio pada $w_{2}$ mengalami peningkatan. Hal ini menunjukkan bahwa saham Bank Mandiri tidak mengalami penu- 
30 Citra Ariadini Chairunnisa

\begin{tabular}{|c|c|c|c|c|c|}
\hline$\tau$ & w1 & w2 & w3 & $\mu_{w}$ & $V a R_{w}$ \\
\hline 0 & 0,1976 & 0,6034 & 0,1990 & $-0,00091899$ & 0,0013453 \\
\hline 0,1 & 0,1968 & 0,6048 & 0,1984 & $-0,00091855$ & 0,0013445 \\
\hline 0,2 & 0,1959 & 0,6063 & 0,1978 & $-0,00091811$ & 0,0013437 \\
\hline 0,3 & 0,1950 & 0,6078 & 0,1972 & $-0,00091765$ & 0,0013429 \\
\hline$\vdots$ & $\vdots$ & $\vdots$ & $\vdots$ & $\vdots$ & $\vdots$ \\
\hline 7,4 & 0,0146 & 0,9220 & 0,0634 & $-0,00082339$ & 0,0011939 \\
\hline 7,5 & 0,0070 & 0,9352 & 0,0578 & $-0,00081944$ & 0,0011863 \\
\hline 7,6 & $-0,0009$ & 0,9491 & 0,0518 & $-0,00081527$ & $0,0011722+0,000004 \mathrm{i}$ \\
\hline
\end{tabular}

Gambar 5. Proporsi, ekspektasi portofolio dan Value at Risk

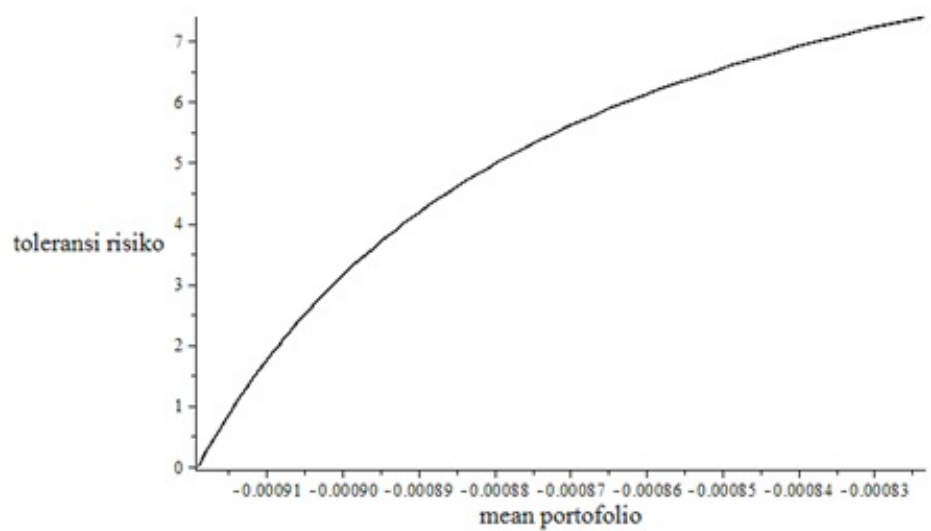

Gambar 6. Grafik Hubungan antara Mean portofolio dengan toleransi risiko

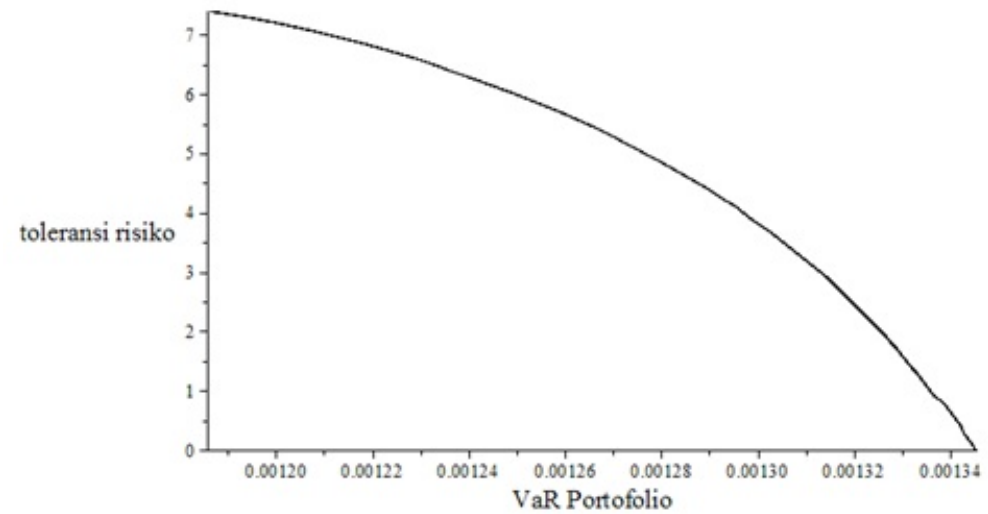

Gambar 7. Grafik Hubungan antara VaR portofolio dengan toleransi risiko 
runan bobot portofolio dengan meningkatnya nilai toleransi risiko. Dari Gambar 5 bobot portofolio optimal dari masing-masing saham saat $\tau=0$ adalah BDMN $=$ $19,76 \%$, BMRI $=60,34 \%$ dan BNGA $=19,90 \%$. Karena VaR merupakan metode dalam mengukur nilai risiko maka dari Gambar 5 diperoleh nilai risiko yaitu 0,00138035. Hal ini berarti risiko dari portofolio yang terbentuk sangat kecil yaitu $0,13 \%$ sehingga aman bagi investor dalam berinvestasi.

\section{Kesimpulan}

Dari hasil pembahasan mengenai pengukuran nilai risiko portofolio saham berdasarkan Mean-VaR dengan saham sektor Perbankan pada periode yang sama yaitu 12 Oktober 2016 - 12 Oktober 2017 diperoleh beberapa kesimpulan, yaitu

(1) Dari 33 saham Perbankan yang digunakan menjadi komposisi saham dalam portofolio saham terdiri dari 3 saham yaitu Bank Danamon Indonesia Tbk, Bank Mandiri (Persero) Tbk dan Bank CIMB Niaga Tbk.

(2) Berdasarkan perhitungan bobot portofolio, dengan nilai toleransi risiko yang terus meningkat terjadi penurunan bobot portofolio pada saham Bank Danamon Indonesia Tbk dan Bank CIMB Niaga Tbk, sedangkan saham Bank Mandiri (Persero) Tbk mengalami peningkatan bobot portofolio.

(3) Terjadi penurunan yang pada bobot saham Bank Danamon Indonesia Tbk dengan bertambahnya nilai risiko, sehingga investor harus waspada terhadap kinerja portofolio.

(4) Bobot portofolio untuk masing-masing saham dengan risiko minimum yaitu 0 adalah 18,36\% saham Bank Danamon Indonesia Tbk, 13,14\% saham Bank Pembangunan Daerah Jawa Timur Tbk, 52,00\% saham Bank Mandiri (Persero) Tbk dan 16,50\% saham Bank CIMB Niaga Tbk

(5) VaR merupakan metode dalam mengukur nilai risiko, sehingga berdasar-kan nilai VaR portofolio maka diperoleh nilai risiko portofolio berdasar-kan meanVaR adalah 0,00138035 .

\section{Daftar Pustaka}

[1] Bain, L.J and M. Engelhardt. 1992. Introduction To Probability and Mathematical Statistics. Second Edition. Duxbury Press, California

[2] Best. 1998. Implementing Value at Risk. John Wiley \& Sons Ltd, Chichester

[3] Dumairy. 1998.Matematika Terapan untuk Bisnis dan Ekonomi. BPFEYogyakarta, Yogyakarta

[4] Jogiyanto. 2000.Teori Portofolio dan Analisis Investasi. Edisi Kedua. BPPE, Yogyakarta

[5] Masrukan, E. 2013.Optimalisasi Nilai Risiko Portofolio Saham Berdasarkan Mean-VaR. Jurnal Matematika Universitas Brawijaya, Malang

[6] Ni'mah, Khoirun. 2015.Pengukuran Nilai Risiko Portofolio dengan Mean-VaR Menggunakan Simulasi Monte Carlo Berdasarkan Data Historis. Jurnal Matematika Universitas Brawijaya, Malang

[7] Rachev, S.T, S.V.Stoyanov and F.J. Fabozzi. 1990.Advanced Stochastic Models, Risk Assessment, and Portfolio Optimization. John Wiley and Sons,Inc., Canada 
32 Citra Ariadini Chairunnisa

[8] Tandelilin. E. 2001. Analisis Investasi dan Manajemen Portofolio. Edisi Pertama. BPFE-Yogyakarta, Yogyakarta 